http://dx.doi.org/10.22402/j.rdipycs.unam.3.2.2017.134.179-195

\title{
HUMOR, VIOLENCIA Y ÁMBITO UNIVERSITARIO
}

\author{
Irene Aguado-Herrera y María Teresa Pantoja-Palmeros \\ FES Iztacala, UNAM \\ México
}

\section{RESUMEN}

El presente artículo tiene como objetivo analizar el humor y la risa como estrategias subjetivas que permiten elaborar y trasformar las violencias presentes en el proceso de formación. La investigación se realizó a partir de un dispositivo grupal denominado "Taller de Investigación Implicación: Violencia y Ámbito Universitario”, dirigido a alumnos y egresados de la carrera de Psicología de la Universidad Nacional Autónoma de México, FES Iztacala.

Palabras Clave:

Violencia(s), humor, grupo y ámbito universitario

\section{HUMOR, VIOLENCE AND UNIVERSITY ENVIRONMENT}

\section{ABSTRACT}

This article analyses the role of humor and laughter strategies that can contribute to apprehend and transform forms of violence that take place during higher education. The study was conducting using a group device called: "analyses and engagement workshop: violence and higher education". All participants in these seminars were students and alumni from the psychology program at the Iztacala campus of the National Autonomous University of Mexico.

\section{Keywords:}

violence, humor, group, higher education 


\author{
HUMOR, VIOLENCIA Y ÁMBITO UNIVERSITARIO
}

\author{
Irene Aguado-Herrera y María Teresa Pantoja-Palmeros \\ FES Iztacala, UNAM \\ México
}

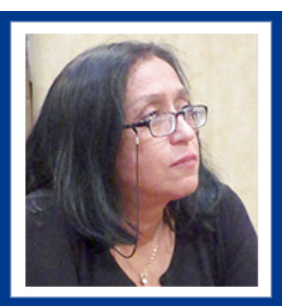

Irene Aguado-Herrera

FES Iztacala, UNAM

Correo: ireneag@unam.mx

Doctora en Educación por la UPN, Especialidad: Práctica psicoanalítica posicionamiento ético ante el dolor, Colegio de Saberes, Formación en Sociología Clínica con Vincent de Gaulejac París VII Laboratorio de Cambio Social. Profesor Titular A T.C. UNAM FES Iztacala Carrera de psicología.

Ver más...

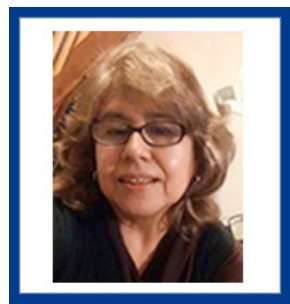

María Teresa Pantoja-Palmeros

FES Iztacala, UNAM

Correo: mtpantjo@unam.mx

Actualmente cursa el Doctorado en Saberes sobre Subjetividad y Violencia en el Colegio de Saberes. Profesora Asociado "B" Tiempo Completo en el Área de Psicología Social Teórica de la Facultad de Estudios Superiores Iztacala de la UNAM.

Ver más...

\title{
CONTRIBUCIÓN DE LAS AUTORAS
}

Se atribuye a amabas autoras por igualdad la autoría de la presente investigación

\section{AgRADECIMIENTOS}

Esta publicación fue posible gracias al apoyo del proyecto PAPCA "Subjetividad y Procesos Educativos" (FESI-DIPPAPCA-2016-22). FES Iztacala, Universidad Nacional Autónoma de México. Responsable doctor José Refugio Velasco García; corresponsable doctora Irene Aguado Herrera.

\section{Datos de Filiación de las Autoras}

Facultad de Estudios Superiores Iztacala, UNAM.

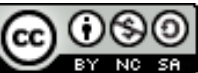

Copyright: (c) 2017 Aguado-Herrera, I., Pantoja-Palmeros, M.T.

Este es un artículo de acceso abierto distribuido bajo los términos de la licencia Creative Commons Reconocimiento-NoComercial -Compartirlgual 4.0 Internacional, por lo que su contenido gráfico y escrito se puede compartir, copiar y redistribuir total o parcialmente sin necesidad de permiso expreso de sus autoras con la única condición de que no se puede usar con fines directamente comerciales y los términos legales de cualquier trabajo derivado deben ser los mismos que se expresan en la presente declaración. La única condición es que se cite la fuente con referencia a la Revista Digital Internacional de Psicología y Ciencia Social y a sus autoras. 


\section{TABLA DE CONTENIDO}

INTRODUCCIÓN

VIOLENCIA, SUS INTERPRETACIONES Y EL HUMOR

MetodologíA

Objetivo de la investigación, 26

Objetivo de intervención, 26

Consideraciones metodológicas sobre el dispositivo, 26

RESULTADOS

Los sentidos generados en las dramatizaciones y el humor, 27

Representaciones, 27

DISCUSIÓN Y CONCLUSIONES 


\section{INTRODUCCIÓN}

$\mathrm{E}$ n el presente texto expondremos una línea de análisis que hemos trabajado como parte del proyecto de investigación que realizamos en relación con los procesos subjetivos presentes y articulados en la educación, particularmente en el ámbito universitario. El responsable de este proyecto es el doctor José Refugio Velasco García y la corresponsable es la doctora Irene Aguado Herrera.

La premisa de que partimos es que todo proceso educativo es posible y se sostiene en los procesos subjetivos que en él se articulan, tensan, complementan y contradicen. Entre estos procesos subjetivos, adquieren un papel relevante los que remiten y hacen patente el orden de lo inconsciente de los sujetos involucrados en la institución, en el proceso y en la tarea educativa. Sujetos que son a la vez agentes y objetos de los procesos de subjetivación y de desubjetivación.

En los diferentes dispositivos grupales que se han diseñado e implementado como parte de la investigación, uno de los aspectos que se ha hecho presente de manera reiterada es el referente a la presencia de actos de violencia en el ámbito universitario y en el proceso de formación específicamente; también se ha trabajado y analizado el humor como método o estrategia subjetiva que permite la elaboración y resignificación de la violencia. Por tal razón el objetivo en este trabajo es mostrar los aspectos del humor y la risa que se produjeron en un espacio confeccionado específicamente para explorar la violencia en la institución universitaria.

\section{VIOLENCIA, SUS INTERPRETACIONES Y EL HUMOR}

En la universidad como en cualquier espacio social se despliegan, se abordan y desbordan, problemáticas contemporáneas que causan un malestar en el sujeto. En el espacio universitario el fenómeno de la violencia se manifiesta de muchas formas y ha sido abordado desde muchos puntos de vista, dando lugar a distintas interpretaciones en torno a ese fenómeno humano y sólo nos estamos refiriendo a interpretaciones de orden teórico y metodológico, donde el pensamiento académico parece aclarar los motivos y consecuencias de la violencia.

También se dan interpretaciones espontáneas de quienes están vinculados con sus emblemas, sus sistemas de organización administrativa, sus jerarquías de poder y sus finalidades explícitas e implícitas. Muchas de dichas interpretaciones tienen la intención de esclarecer el devenir de la violencia; simplemente se producen en las relaciones sociales cotidianas, dentro de las geografías específicas que habitamos. Emergen de manera espontánea y su destino es incierto, se olvidan con mucha rapidez, no trascienden en el tiempo, pero en ocasiones dejan huella indeleble en la memoria de los grupos que le dan vida a la institución.

La violencia ha sido analizada desde una gran diversidad de discursos y en diferentes ámbitos, situaciones y espacios, por lo que no se tiene un concepto unívoco y general de violencia. Por esta razón, cada autor e investigador tiene el reto de delimitar conceptualmente su punto de partida y hacerlo explícito. En nuestro caso partimos de los conceptos freudianos de pulsión y de pulsión de muerte, articulándolas a los fenómenos inconscientes. Retomamos lo planteado por Freud (1920) para proponer a la violencia como una manifestación de la pulsión de muerte, sin que con ello pretendamos agotar lo que respecto a este rasgo humano se pueda decir.

En este sentido, Gerber (2006: 191) señala que "[...] la violencia se encuentra en el núcleo mismo de lo humano", ya que el carácter violento de la pulsión tiene su origen en el propio acto violento que constituye al hombre desviándole del orden natural, y con ello instituyendo el orden social, en el cual se dará lugar a la constante tensión entre orden y caos, vida y muerte, creación y destrucción.

De las múltiples funciones y materialidades de la violencia, aquí nos enfocaremos sólo a la manifestación que

[...] encuentra su fundamento en la negación del otro, rompe toda posibilidad de juego entre los sujetos involucrados, hace del sujeto un objeto, objeto de exterminio, de placer, de uso o abuso. Lo desaparece como sujeto al imponer su fuerza, más que debilitar la capacidad de resistir, la quiebra, la anula, la cercena; la libertad es abolida, el reconocimiento del otro es borrado [...] la otredad se vuelve objeto a destruir, a exterminar, o bien a abusar (García, 2005: 118).

Desde el psicoanálisis la posibilidad que se abre ante la violencia:

[...] es la de transformar ese goce, destructivo y mortífero en su esencia, en acto creador, hacer del lenguaje que trae consigo la vida y condena a la muerte, el espacio donde siempre sea posible que una palabra diferente ponga un límite siempre provisional al empuje arrollador de eso que no dejará de cuestionarlo, parte maldita, pulsión de muerte, goce, que deben ser reconocidos en su importancia y su valor para mantenernos vivos en el deseo (Gerber, 2007: 209).

Como se indicó, la violencia es inherente al sujeto y se expresa permanentemente, por lo que irrumpe 
en toda institución, y la educativa no es la excepción. La institución educativa hija y heredera del proyecto de la modernidad tiene entre sus propósitos fundamentales la homogenización, el control y la disciplina de los miembros de la sociedad, para lo cual es necesaria la existencia de un juego, de un entramado de poder. Sin embargo, como señala Anzaldúa (2016: 77-78):

también tienen lugar en el seno de la institución educativa y entre todos los agentes que en ella se encuentran, expresiones de violencia de manera aceptada, naturalizada, normalizada e incluso institucionalizada, que no sólo son un ejercicio del poder, sino un abuso tendiente a la intimidación, la humillación, la domesticación o el sometimiento, logrando un acostumbramiento de prácticas y pautas de conducta, controles, estigmas, violencias institucionales verbales o escritas, que son aceptadas sin mayor reflexión.

Respecto al humor, encontramos que Freud (1981: 2998) señala que "lo grandioso reside a todas luces en el triunfo del narcisismo, en la victoriosa confirmación de la invulnerabilidad del yo. El yo rehúsa dejarse ofender y precipitar al sufrimiento por los influjos de la realidad; se empecina en que no pueden afectarlo los traumas del mundo exterior; más aún: demuestra que sólo le representan motivos de placer".

Se puede afirmar que el humor es rebelde; lo curioso es que Freud (1981: 2998) dice que esta rebeldía comparte con el síntoma "procesos regresivos y reaccionarios", escamoteando el sufrimiento del yo. Nuestro autor sitúa el humor al lado de la neurosis, la embriaguez, el retraimiento y la propia locura: "El humor debe a esta vinculación una dignidad que le falta del todo, por ejemplo, al chiste, pues este sirve tan sólo al beneficio placentero, o bien pone esta ganancia al servicio de la agresión".

No profundizaremos por ahora en las diferencias que establece Freud entre el chiste y el humor; sólo nos concentramos en esta dignidad o superioridad que adquiere el yo ante los sufrimientos de la vida y que resalta el fundador del psicoanálisis. El humor es, pues, una forma de enfrentar con valor esos sufrimientos, de demostrar al mundo y a sí mismo que todavía se puede encontrar algo de placer en un mundo trágico. El yo minimiza así ese sufrimiento con las armas del humor, jugando con el lenguaje y generando un estado afectivo. El humor parece indicarnos: "¡Mira, ahí tienes ese mundo que te parecía tan peligroso. No es más que un juego de niños, bueno apenas para tomarlo en broma!" (Freud, 1981: 3000).

Lo interesante aquí es que en el juego del humor está involucrado el lenguaje, la risa que muestra un estado afectivo placentero, al tiempo que el superyó expresa su fas amable, de tal manera que surge una voz que se torna protectora y solidaria con el yo. Creemos que esta combinación de elementos lleva a Freud en este texto a decir que, si en el humor el superyó habla cariñosamente, entonces "tenemos muchísimo que aprender acerca de la esencia del superyó" (Freud, 1981: 3000).

No podemos olvidar que en varios momentos de su obra, Freud aborda el carácter obsceno y feroz del superyó, lo cual contrasta con la manera en que en el texto sobre el humor reivindica el rostro amable de esa instancia del aparato psíquico. Por ejemplo, en La disección de la personalidad psíquica, se describe a un superyó que se da a la tarea de mantener la autoridad parental, representando no sólo las normas y leyes a las que debe apegarse un sujeto dentro de la cultura, sino que también reúne costumbres y hábitos familiares, populares, raciales, incorporando subrogados parentales como los maestros, personajes ejemplares o ideales admirados por la sociedad. En ese texto se llega a decir que aunque la educación de los padres haya sido benigna, la estructura superyoica desarrolla por sí misma funciones feroces, punitivas, sancionando al yo y haciéndole pagar por cosas que fueron ya castigadas en el pasado. Es en el texto sobre el humor, una de las pocas ocasiones en que Freud asigna al superyó un carácter amable, protector y benevolente y ubica al humor como un Don, una estrategia, un recurso para que el yo enfrente y transforme la violencia.

Freud mismo ofrece una prueba de ello cuando, hacia el año 1938, en Viena, después de haber pasado por situaciones terribles, ya que su hija había estado en manos de la Gestapo, su casa había sido revisada por los nazis y él se había sometido a 23 operaciones en la mandíbula a causa del cáncer; al recibir a su viejo amigo vienés Walter Schmideberg en su casa de Londres lo saludó con un "¡heil Hitler!", como si consintiera por fin en pronunciar, a través de ese chiste lúgubre, el nombre infame del destructor de su obra" (Roudinesco, 2016: 442).

Con este marco de referencia en nuestra investigación, uno de los soportes metodológicos empleado ha sido el psicodrama, donde el humor y la risa como expresiones subjetivas han desempeñado un papel importante en un espacio confeccionado específicamente para explorar la violencia en la institución universitaria. El psicodrama es una estrategia de investigación e intervención que, aunque tiene su origen en el campo teatral, se ha implementado en diferentes escenarios, con diversos objetivos y desde diferentes discursos teóricos. El psicodrama orientado psicoanalíticamente, según Basquin, Duboisson, Samuel-Lajeunese y Testemale-Monod (1977) y Safouan, (1979), permite actualizar en el aquí y el ahora una situación que se vive como coagulada, reificada, Cosificada. Al darle vida, al movilizarla, los involucrados incluyen sus cuerpos, su palabra, sus emociones y otra 
temporalidad. En la puesta en escena se interpreta, y por lo tanto se modifica, la representación de lo acontecido, a lo que se remite o alude. Tenemos así algo que no es repetición sino posibilidad de reubicarse, de generar nuevos sentidos de esa escena anterior, dando lugar a una nueva escena en la que se intenta, se ensaya la posibilidad de reelaborar vínculos humanos conflictivos; estas nuevas producciones de sentido encaminan hacia una posición subjetiva diferente, a una rectificación donde el sujeto se constituye en actor de la historia, de su historia. Ya que el fin y el objetivo de la acción psicodramática, como señala Massota (1979: 12), son "reinscribir al sujeto en su historia, o bien, es lo mismo, en inscribir las condiciones de esa historia en el sujeto".

El trabajo grupal genera las condiciones para que lo evocado que se pone en acto, en un aquí y ahora, "en un hacer como si", dé lugar a que en los participantes se produzca la reviviscencia, con la intención de que se generen re-significaciones producidas grupalmente. Asimismo, al poner a jugar el cuerpo para encarnar personajes reales o ficticios, tenemos la posibilidad de enfrentar a protagonistas de carne y hueso, lo cual nos puede permitir percibir los efectos de la repetición, así como la posibilidad de crear nuevas interpretaciones, descubrir estrategias y recursos subjetivos; tanto para los que escenifican el acontecimiento a que se hace referencia, como para aque

éllos que son espectadores de la dramatización. Como se puede apreciar, lo singular y lo grupal son dos dimensiones que se movilizan en este tipo de trabajo que permite y requiere la participación creadora y activa del humorista o los humoristas. Creación humorística que modifica no a la situación o acontecimiento vivenciado y representado, sino a los que ponen en juego el humor, su humor. De ahí que Lieberman (2005: 126) señale, respecto al humor, que "es una medicina para lo incurable, a la vez inútil y eficaz".

\section{Metodología}

\section{Objetivo de la investigación}

Analizar los actos de violencia que tienen lugar y de los que somos sujetos y objeto en el ámbito universitario (FES-Iztacala/Psicología) en el proceso de formación.

\section{Objetivo de intervención}

Que los participantes puedan producir un cambio de posición subjetiva acerca de la violencia presente en las instituciones educativas, que permita otras modalidades de convivencia.

\section{Consideraciones metodológicas sobre el dispositivo}

Una de las estrategias para avanzar en la dirección señalada es haber implementado en cuatro ocasiones un dispositivo grupal con el método clínico denominado "Taller de Investigación Implicación. Violencia y Ámbito Universitario", dirigido a alumnos y egresados de la carrera de Psicología. La convocatoria se ha realizado a través del Programa de Superación Académica de Iztacala, y los grupos se han conformado por un promedio de 10 participantes. Cada taller constó de cinco sesiones, de tres horas de duración cada una, y son coordinados por un equipo de tres psicoanalistas.

El procedimiento que se ha seguido incluye los soportes metodológicos ${ }^{1}$ que se enuncian a continuación de manera general, entre los cuales se encuentra el de la dramatización, el cual se describe detalladamente, toda vez que el análisis que realizamos se centra en lo trabajado con este soporte.

\section{Familiarización.}

1.1. Presentación (nombre y condición escolar).

1.2. Presentación, análisis y firma del consentimiento informado por parte de los participantes del taller.

1.3. Escribir una palabra o idea acerca de la violencia.

1.4. Escribir una palabra o idea sobre sus expectativas del taller.

2. Técnica de caldeamiento grupal.

3. Resurgencia al inicio de cada sesión.

4. Elaboración de un dibujo en el que representen alguna situación que consideren como violenta en el ámbito universitario y su proceso de formación. Narrativa del dibujo por cada uno de los autores.

5. Escritura de un texto de manera individual y anónima de cada uno de los participantes acerca de una situación de violencia que hayan vivido en el ámbito universitario y su proceso de formación, y que no han podido hablarla con alguien y, por tanto, les genera malestar.

6. Dramatización de una escena en la que representen alguna situación que consideren como violenta en el ámbito universitario y su proceso de formación, que haya sido plasmada en el dibujo realizado en el soporte 4 . El procedimiento que se sigue en este soporte metodológico es el siguiente.

6.1. El día anterior se les invita a que lleven utilería y el equipo coordinador también proporciona material (sombreros, gorras, mascadas, bigotes, etcétera). 6.2. Los participantes se dividen en dos equipos.

1 Acerca de la fundamentación y justificación de los soportes metodológicos empleados, véase Aguado (2016). 
6.3. Cada equipo elige de entre las escenas dibujadas por los integrantes del equipo la que quieren representar, y se asignan los roles.

6.4. Cada equipo hace la representación que eligió y, al término de la representación, todos pueden participar comentando acerca de lo que sintieron o pensaron.

6.5. A partir de lo elaborado se vuele a re-escenificar, incluyendo los cambios que deseen. Se puede modificar: la conformación del equipo, cambiar los roles y el contenido de la escena.

6.6. Al término de la representación, todos pueden participar comentando acerca de lo que sintieron o pensaron.

7. Cierre y devolución.

\section{Resultados}

\section{Los sentidos generados en las dramatizaciones y el humor}

A lo largo del trabajo con los diferentes soportes se identificó una amplia gama de acciones violentas en las que los participantes se reconocieron como sujetos y objeto de las mismas. También se localizó una variedad de situaciones y agentes de violencia, señalando como una constante las que se ejercen por parte del profesorado, desde las más sutiles (descalificaciones, falta de respeto) hasta acoso y abuso sexual, por lo que este fue un contenido frecuente en las dramatizaciones.

De las dramatizaciones que se realizaron en los diferentes talleres analizaremos sólo aquéllas en que se recurrió al humor como estrategia subjetiva privilegiada al momento de plantearse la re-escenificación. El humor se tornó un medio que abría la posibilidad de enfrentar la ansiedad, la ira, el temor, la vulnerabilidad, mostrando el grado de implicación de los participantes, al mismo tiempo que se tomaba distancia de lo acontecido promoviendo un cambio de posición desde la cual se recuperaban ellos como sujetos, descolocando al otro del lugar de poder desde el cual ejerció el acto violento.

Es importante destacar que la dramatización permite la inclusión de otros recursos tanto intrasubjetivos como intersubjetivos (grupales), lo que propicia la emergencia del humor; sin embargo, ésta por sí misma no garantiza que se disponga de aquél como estrategia o método, ya que dependerá tanto de los recursos subjetivos de los participantes como de las características de la grupalidad, lo que confirma lo señalado por Freud en el sentido de que el humor es un Don raro y precioso.

\section{Representaciones}

\section{El maestro nacionalista}

La escena elegida para ser representada fue la que una de las participantes recordó que cuando estuvo en la preparatoria y uno de sus compañeros llevaba puesta a una de las clases una chamarra con la bandera de Estados Unidos. El maestro, iracundo, le dijo que se quitara la chamarra porque era indignante que estuviera ese símbolo en un espacio de educación aquí en México; el chico se resistió a quitársela, por lo que el maestro lo obligó a retirarse del salón.

Para la dramatización los participantes del taller trajeron utilería y acordaron escenificar esa situación. Traían una bandera de México, otra de Estados Unidos muy pequeña, una del equipo de futbol de la UNAM, sombrero, bigotes, lentes muy grandes sin micas, pelucas y sacos. Se pusieron de acuerdo y formaron un escenario donde simulaban un salón de clase. Uno de ellos se vistió de maestro (portaba bigote, sombrero, saco y la bandera de México puesta como delantal) y comenzó a hablar con un tono norteño. Una integrante asumió el papel de alumna, tomó la banderita de Estados Unidos y se la puso en su suéter. El maestro muy indignado regañó a la alumna y le dijo que si no se quitaba esa chamarra con la bandera de Estados Unidos mejor se saliera del salón. Pero la estudiante le dijo que tenía frío, además que no ofendía a nadie. Sus compañeros la empezaron a defender y comenzó la discusión. En ese momento quien actuaba de profesor, simulando sacó a patadas a la alumna, y se generalizó la risa, sobre todo cuando el que más serio se mostraba era él, con su tono de norteño y con todo ese disfraz tan hábilmente caracterizado. Surgió la risa porque los asistentes tuvieron la habilidad de representar las experiencias vividas anteriormente de manera graciosa y divertida.

\section{La maestra iracunda}

Otra escena representada fue planteada en los siguientes términos. Al grupo del que forma parte Adriana $^{2}$, en una de las prácticas que realizan como parte de su formación, les correspondió organizar un evento en la explanada de la escuela, en el cual se realizaron diferentes actividades dirigidas tanto a la población interna de la escuela como a la comunidad aledaña. El día previsto Adriana llegó a la explanada con el material de apoyo para la actividad con un retraso de algunos minutos; al verla la maestra de la práctica le gritó que se apurara y cuando estuvo cerca,

2 El nombre de la participante se ha cambio a efecto de conservar el anonimato. 
enfrente de sus compañeros le reclamó su impuntualidad, gritándole muy agresivamente, utilizando además adjetivos negativos para referirse a ella, a sus ademanes y a su desempeño académico. Ante esta situación, Adriana sólo lloró y una de sus compañeras y amiga intervino para consolarla y entonces también ella fue objeto de regaños y malos tratos por parte de la maestra.

La primera vez que se habló de esta situación aparecieron sentimientos de ansiedad, enojo y desconcierto, además hubo lágrimas. De esta manera se hizo patente la imposibilidad de manejar una situación en la que hubo abuso por parte de alguien con poder y autoridad. La persona directamente afectada recordó la situación y dijo que después de eso permanentemente aparecía el deseo de abandonar la escuela. Otros tres compañeros participantes del taller, y que también habían presenciado esa situación y recordaban junto con ella, mostraron evidentes estados de frustración, enojo y tristeza.

Al pasar a la dramatización, encontramos dos tiempos diferenciados. En el primero de ellos la escena se representó tal y como la recordaban; en el segundo tiempo, que llamaremos "reescenificación", se dio un giro importante, ya que se introdujeron elementos de burla y ridiculización, enfatizando las características físicas y el comportamiento de la maestra, lo cual les permitió poder actuar atribuyéndose la posibilidad de enfrentar la violencia cuestionando tanto la forma como el contenido del acto violento. Poder introducir el humor, y con él reírse de la situación, les permitió no sólo desdramatizar, sino mirar también desde otro ángulo el lugar donde el otro se ubicó al ser violento, mostrando cómo se descolocó de un lugar de autoridad legítima al ponerse fuera de control y congruencia, haciendo patente cómo, ante la falta de argumentos, aparece la descalificación. Esto, que no fue posible de realizar en el momento en que sucedió la violencia, se hizo evidente al recrear y resignificar lo acontecido. La vivencia de humillación y desvalorización se pudo transformar en posibilidad de elaboración y reivindicación de quienes sufrieron la agresión, lo cual les permitió incluso pensar no sólo su lugar como agredidos, sino el lugar del otro que, atrapado por la violencia, hace evidente sus propias imposibilidades. Con esto lograron descolocarse del lugar de objeto de violencia (humillación y descalificación) y recuperarse como sujetos con derechos y responsabilidades.

\section{DisCUSIÓN Y CONCLUSIONES}

Los peores momentos se pueden tornar divertidos. En las dos viñetas expuestas se ilustra cómo en un dispositivo para explorar la violencia, en la dramatización, los participantes pusieron en acto sus recursos subjetivos singulares y grupales para, de manera lúdica, traer al presente experiencias que en el pasado los hicieron sufrir. En el juego y con el juego se reescribe la historia y el sujeto mismo. En este sentido Morales (1997: 168) dice:

En el juego, el niño no sólo intenta anudar historias sino que eso le produce alegría. ¿Por qué una niña ríe cuando juega? Porque está creando un texto nuevo a partir de otros textos. Jugar es descubrir las bondades del lenguaje; es inventar nuevas historias; es asistir a la posibilidad humana de crear nuevos latidos, y eso es maravillosamente placentero.

El juego del niño es muy serio, pero no es solemne. A la seriedad gozosa del niño, a esa risa y concentración ante el invento espontáneo, la humanidad respondió con rito y solemnidad. La religión hizo del juego, rito; y de la seriedad de lo allí jugado, solemnidad. [...] Los dioses griegos jugaban y se reían; el dios monoteísta es serio y solemne.

Así, el sujeto le imprime pulsión de vida a lo quebrantado, se dignifica al manejar el mundo de los objetos materiales y de los sentimientos, juega con ellos, los cambia de lugar; también pone en juego su cuerpo. El humor entonces aparece como una posibilidad de no dejarse someter por el otro, y que si ese sometimiento ocurrió en el pasado, podemos suspender ese sometimiento para que no se vuelva un eterno retorno.

Las dramatizaciones permitieron jugar con las situaciones violentas y ocasionar risa; aquí también se crearon otros textos y otros estados de ánimo. La recreación se volvió creación ante lo doloroso; al malestar del pasado se le puso un sombrero y un bigote, se le ridiculizó al tiempo que surgía la carcajada.

En esta experiencia, la violencia se reconoció en diferentes ámbitos de nuestra vida cotidiana y específicamente dentro del ámbito universitario se vislumbraron algunas de sus diversas manifestaciones: como violencia enmascarada en donde los golpes físicos no están presentes. Así, pudimos situar a la violencia, de acuerdo con Zizek (2009), quien señala que la violencia tiene diversos rostros donde podemos encontrar desde actos criminales, de terror, disturbios civiles y conflictos mundiales. Todos estos como actos muy visibles. 
Pero hay una violencia encarnada en el lenguaje. Bordieu (1999) sitúa esta forma de expresión como una violencia simbólica, como esa forma de someter y dominar al otro por medio del poder, e incluso la generosidad, lo cual puede producir un sentimiento de deuda y responsabilidad que son difíciles de pagar; específicamente hablamos de los Dones y su otorgamiento.

La ansiedad, el miedo, la vergüenza, la violencia y la agresión se expresaron en el trabajo grupal, permitiendo transformarlas en productividad y en creatividad. Primero se produjeron palabras habladas, escritas, relacionadas con el odio y venganza hacia quienes ubican como agentes de la violencia. Recordar y elaborar en la intimidad del grupo las historias de acoso, de abuso, vividas como dolorosas dio lugar a un nivel de simbolización que no podemos despreciar, pasando del cuerpo mudo a la palabra hablada, a la escritura y a la puesta en acto de un hacer como sí.

Al reflexionar acerca de la representación uno de los participantes comentó: "los peores momentos también se pueden tornar divertidos". Nosotros señalamos: no sólo Hollywood puede crear argumentos y escenas divertidas, también ustedes lo hicieron. Se rieron de la agresión, de la violencia, se mostraron violentos con la violencia por medio del humor y la risa; parece que ahora la derrotaron. Así se demuestra que el recurso del humor no sólo ofrece al yo la cara benevolente del superyó, sino que además abre la posibilidad de una salida, una solución exitosa, en este caso ante la violencia, consistente en rectificar no la realidad o el acontecimiento, sino la posición del sujeto que la desafía, se rebela reconstituyéndose como sujeto con dignidad y accede al placer.

Diseñar un dispositivo grupal partiendo del psicoanálisis ha permitido la posibilidad de sostener dos procesos fundamentales: investigar e intervenir. En relación con la investigación fue posible reconocer y dar cuenta de cómo en los procesos subjetivos que se dan en la práctica educativa está presente la pulsión de muerte en las expresiones de violencia de diversa índole, desde las sutiles hasta las más evidentes, generando efectos tanto en el propio proceso educativo como en los sujetos que lo sostienen. Respecto a la intervención al permitir que los participantes pusieran en palabras o en actos los acontecimientos violentos rememorados, se generó una representación psíquica y una resignificación que permitió reconocer, develar, desenmascarar las acciones violentas en las que cotidianamente se ven involucrados, abriéndose con ello la posibilidad de poner en juego los recursos subjetivos con que cuentan, o incluso darse otros, específicamente el humor, para enfrentar la violencia y con ello trasformar sus efectos de mal-estar y sufrimiento en posibilidad de cambio y creación. En los dos casos que se representaron fue desenmascarado el efecto desubjetivisante de la violencia al ubicarlos ante el otro como simple objeto, y con ello se dio la posibilidad de cuestionar la verticalidad y la posición de dominio y sumisión en algunos tipos de vínculo maestro-alumno, e incluso imaginar y poner en acto formas distintas de ubicarse y afrontar, tanto de manera singular como colectiva, a la violencia.

En lo expuesto encuentra justificación y razón de ser la implementación de este tipo de dispositivos en tanto espacios suficientemente subjetivizados y operativos para que esa violencia inherente a toda institución, que no se reduce a la violencia legítima y regulada, y que circula permanentemente en la institución educativa, pueda ser objeto de elaboración, resignificación y transformación en algo más creativo y menos destructivo, siendo el humor un recurso psíquico que pudo desplegarse en este sentido.

Entonces, cabe señalar que la implicación es un proceso esencial para realizar y sostener este tipo de dispositivos, ya que la subjetividad de todos los involucrados, tanto los integrantes del grupo como del equipo de coordinación, constituye tanto el material objeto de análisis como el propio trabajo de análisis. Así, los participantes al implicarse, al sentirse concernidos pudieron no sólo hablar de los acontecimientos violentos vivenciados por ellos, sino también al escucharse y escuchar al otro movilizaron sus recuerdos, sus vivencias, sus afectos, sus cuerpos. También se involucraron en los procesos intersubjetivos propios de toda grupalidad, al re-conocerse en el dicho y sentir de los otros: dando lugar a expresiones como "a mí también me ha pasado", "yo también sentí", "eso me recordó", "yo lo avalo" o "me permite evocar".

En las dos viñetas presentadas se hizo patente su implicación en más de una forma: al traer y compartir con el grupo recuerdos íntimos y dolorosos, al encontrar eco en el resto de los integrantes del grupo y haciéndolo suyo para poder grupalmente asumir el reto de re-presentar lo narrado, darle vida y con ello plasticidad al alterar acciones, sensaciones, diálogos, e incluso geografías; se dio una posibilidad creativa, emotiva, dándole sentidos inéditos e inimaginables. Entre ellos, por qué no, la risa como posibilidad de derrotar la pulsión de muerte, provisoriamente, sí, abriendo paso a Eros, a la creación, a la sublimación, con la carga de violencia que también ahí se juega. 


\section{Referencias}

Aguado, I. (2016). Taller elaborativo vivencial: dispositivo de formación, en I. Aguado y J. Velasco (coords.). Escenarios educativos, subjetividad y psicoanálisis. México: Navarra.

Anzaldúa, R., Grajeda, B. (2016). Institucionalización de la violencia, en C. Carrillo, Las violencias en los entornos escolares. Guadalajara: CUSEA-Universidad de Guadalajara.

Basquin, Duboisson, Samuel-Lajeunese y Testemale-Monod (1977). El psicodrama. Un acercamiento psicoanalítico. México: Siglo XXI.

Bourdieu, P. (1999). Meditaciones pascalianas. Argentina: Anagrama.

Freud, S. (1990/1930). El malestar en la cultura. Obras Completas. Tomo XXI, Argentina: Amorrortu.

Freud, S. (1990/1920). Más allá del principio del placer. Obras Completas. Tomo XVIII. Argentina: Amorrortu.

Freud, S. (1981/1927). El Humor. Obras Completas. Tomo III. Madrid: Biblioteca Nueva.
García, M. I. (2005). Poder, violencia y palabra, en Revista Tramas, núm. 25, México: UAM-Xochimilco, pp. 113-128.

Gerber, D. (2007). Violencia, erotismo y pasión, en Marco Jiménez. Subversión de la violencia. México: Juan Pablos/ UNAM, FES-Acatlán.

Gerber, D. (2006). El psicoanálisis en el malestar en la cultura. Argentina: Lazos.

Lieberman, M. (2005). Entre la angustia y la risa. México: UAMXochimilco.

Massota, O. (1979). "Prólogo", en M. Safouan, Reflexiones sobre el psicodrama. Buenos Aires: Argonauta.

Morales, H. (1997). Sujeto y escritura. Lacan el psicoanálisis y la modernidad. Guadalajara: Ediciones de la Noche.

Roudinesco, E. (2016). Freud en su tiempo y en el nuestro. México: Debate.

Safouan, M. (1979). Reflexiones sobre el psicodrama. Buenos Aires: Argonauta.

Zizek, S. (2009). Seis reflexiones marginales. Barcelona: Paidós.

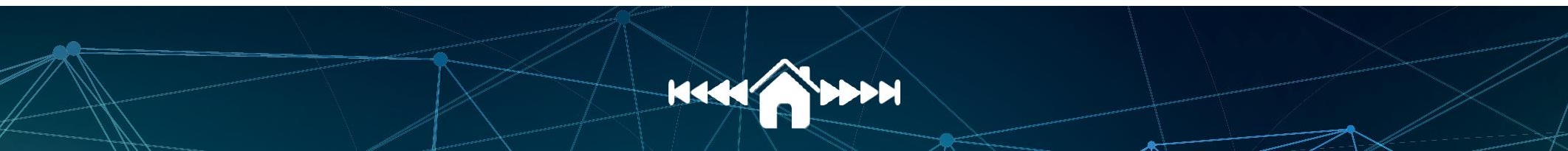




\section{Meta-Análisis del Artículo}


Revista Digital Internacional de Psicología y Ciencia Social | Vol. 3 | Núm. 2 | Juilio-Diciembre 2017| ISSN 2448-8119 e-ISSN $2448-8119$

\section{Dimensión Cuantitativa}

\section{Perfil de Evaluación entre pares}
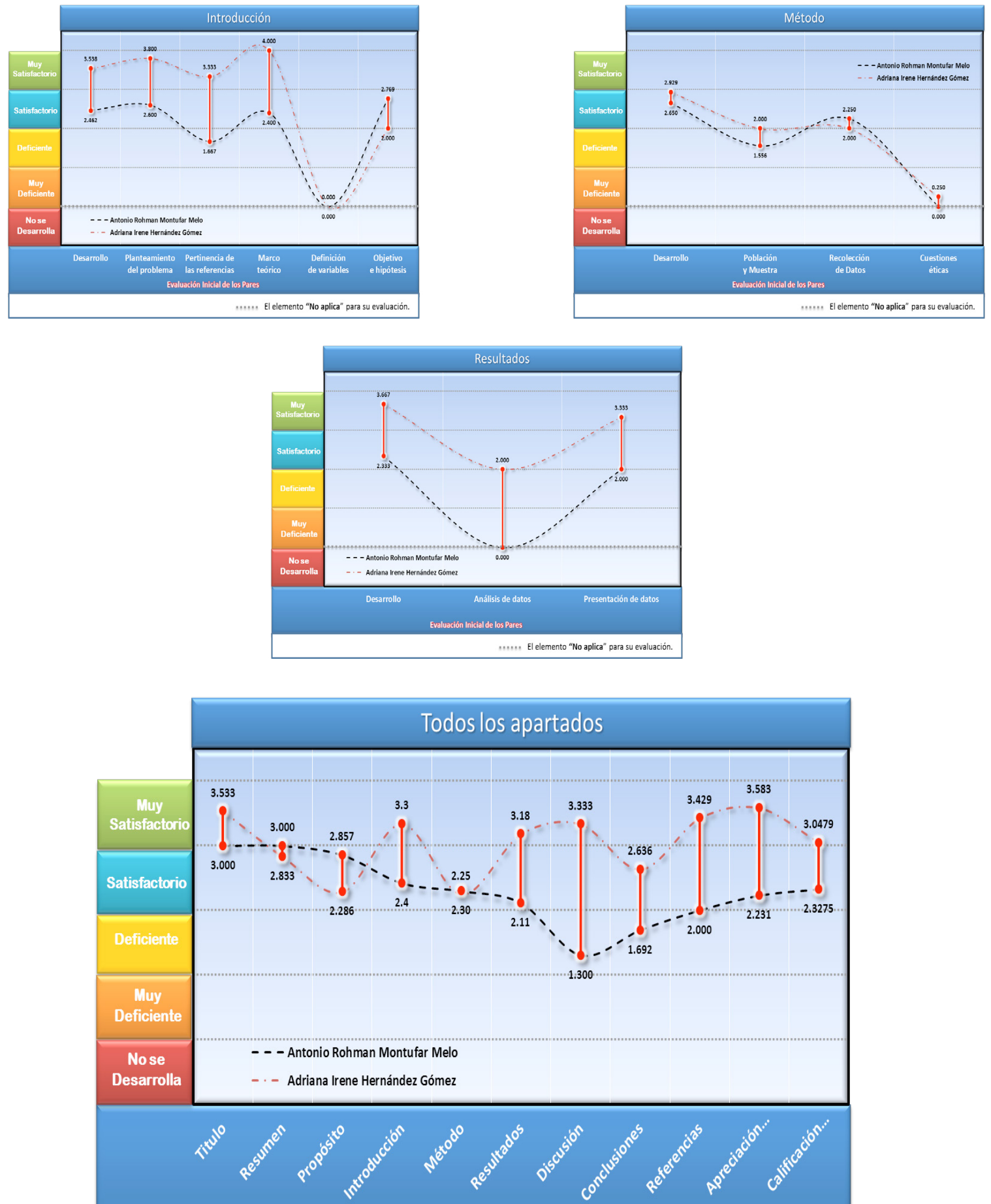


\section{Índice de Concordancia}

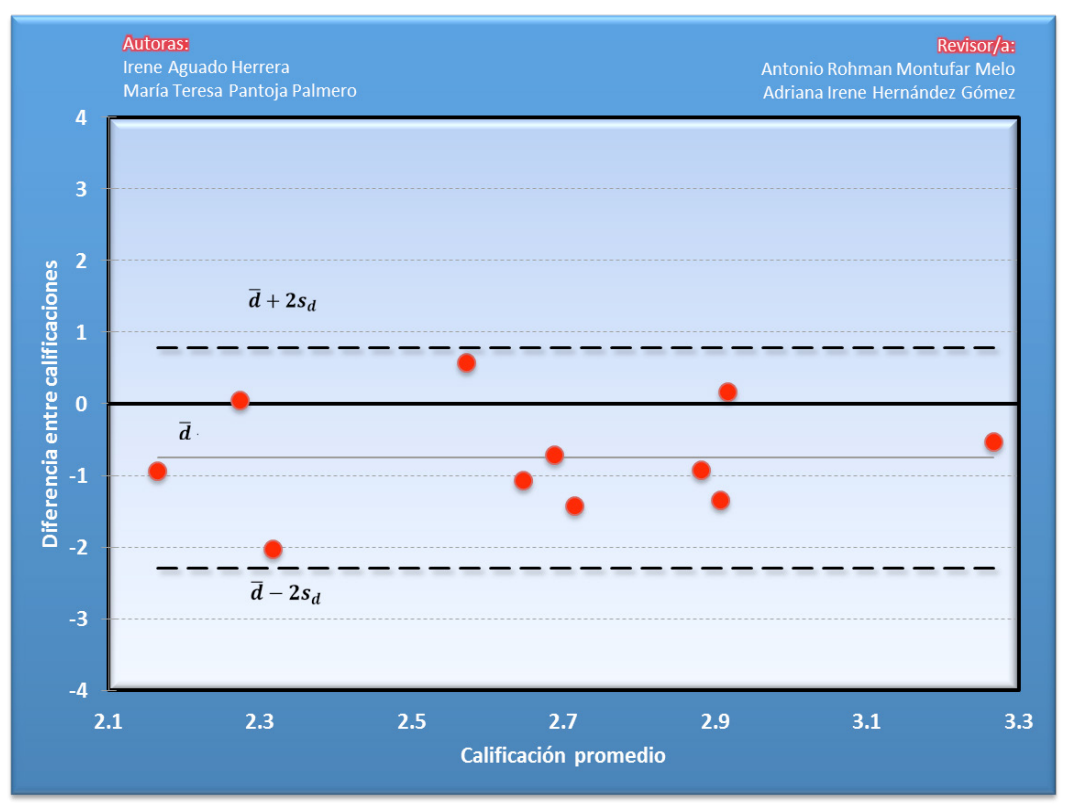

Índice de Acuerdo
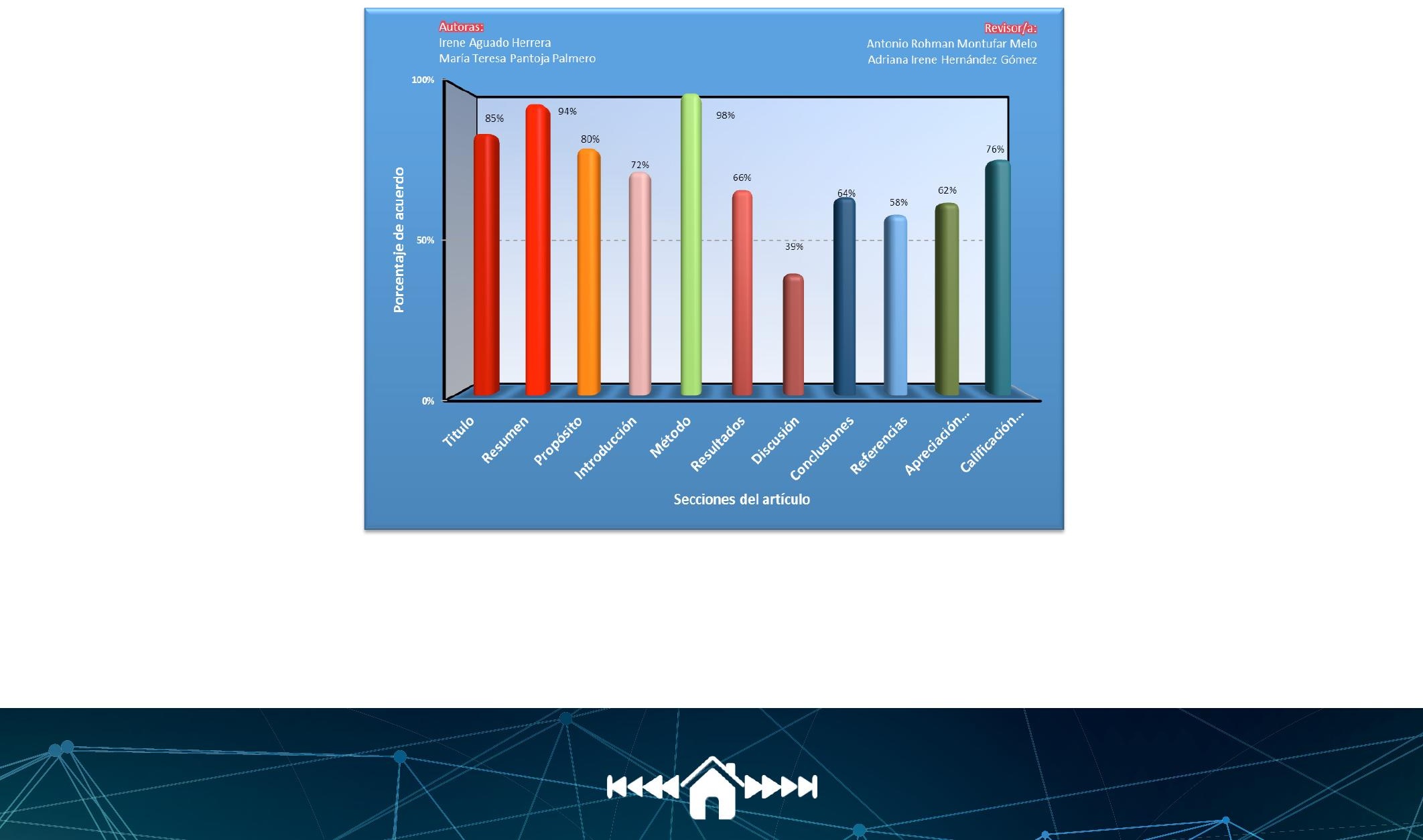


\begin{tabular}{|c|c|}
\hline Revisor 1 & Revisor 2 \\
\hline Antonio Rohman Montufar Melo & Adriana Irene Hernández Gómez \\
\hline \multicolumn{2}{|c|}{ Título/Autoría } \\
\hline $\begin{array}{l}\text { En cuanto al título no hay inconveniente, salvo que no explica } \\
\text { del todo la cuestión referida a los grupos de trabajo, que es rele- } \\
\text { vante en la parte empírica de la investigación. }\end{array}$ & $\begin{array}{l}\text { El título es comprensible y sencillo; sin embargo, es tan abierto a la } \\
\text { interpretación, que es necesario leer el objetivo para saber de qué tra- } \\
\text { ta el artículo. Se sugiere especificar un poco más. Faltaría también } \\
\text { incluir el correo electrónico de las autoras. }\end{array}$ \\
\hline
\end{tabular}

\section{Resumen}

El resumen adolece de ciertas carencias en cuanto a referir los resultados obtenidos; tampoco incluye una idea del planteamiento teórico que respalda todo el trabajo.

\section{Próposito del Estudio}

El propósito queda claro, no hay inconveniente con él.
Se sugiere, para el resumen, complementar la metodología y agregar una breve descripción de lo encontrado, junto con las conclusiones. Adicional a esto, haría falta que las palabras clave reflejen la población con la que se trabajó, así como la visión teórica con la que se trabaja (psicoanálisis).

A lo largo del trabajo, se describen 4 objetivos diferentes. El primero de ellos: "mostrar los aspectos del humor y la risa que se produjeron en un espacio confeccionado específicamente para explorar la violencia en la institución universitaria", es el que corresponde con los resultados y las conclusiones. Sin embargo, los restantes 3 objetivos que se presentan no corresponden. Haría falta, para mejor comprensión del lector, diferenciar o dejar muy claro los objetivos del Proyecto de Investigación "Subjetividad y Procesos Educativos", de los objetivos que tuvo el taller de investigación-implicación que se realizó con los alumnos, para centrarse sobre el humor, objetivo de este artículo. Aún cuando haya otros elementos importantes encontrados en el taller, el centro del artículo debe mostrarse siempre con la cuestión del humor.

\section{Introducción}

El principal problema de esta sección es que el marco teórico está constituido más bien por referencias a autores de muchos años atrás. la información, en su gran mayoría, no se halla actualizada. Las aportaciones de Freu y Anzieu, entre otros, son por demás valiosas, pero deberían ser mayormente acompañadas por otras de fabricación actual. Además, como se verá más adelante, muchas de esas citas no hallan eco en el tratamiento, y por tanto no se ven reflejadas en las conclusiones. Hay, por tanto, una distancia considerable entre el marco teórico y la aproximación empírica.
Se hace una buena revisión teórica del tema; sin embargo, se sugiere incluir, si las hay, algunas investigaciones similares en el tema, así como mostrar de manera mucho más clara las formas en que se presenta la violencia en la formación universitaria. Por último, se sugiere enriquecer con ideas propias de las autoras, las citas textuales que son utilizadas a lo largo de la introducción, analizando y contextualizando el contenido de éstas. 


\begin{tabular}{|c|c|}
\hline Revisor 1 & Revisor 2 \\
\hline \multicolumn{2}{|c|}{ Método } \\
\hline $\begin{array}{l}\text { No hay mayor inconveniente con esta sección, sólo el forma- } \\
\text { to de redacción, y la carencia de una explicación profunda } \\
\text { del por que de las técnicas utilizadas, ya que no hay un fun- } \\
\text { damento teórico que las sustente. }\end{array}$ & $\begin{array}{l}\text { La cuestión del humor, analizada en este artículo, se desprende } \\
\text { de lo encontrado a lo largo del taller en el que participaron los es- } \\
\text { tudiantes. Es decir, a partir de las observaciones de lo ocurrido, se } \\
\text { retoman estos momentos de humor para su análisis. Esto implica } \\
\text { que, de alguna manera, el análisis que se realiza corresponde a } \\
\text { una metodología de corte cualitativo. Se sugiere, para que el ar- } \\
\text { tículo cumpla satisfactoriamente con los criterios metodológicos } \\
\text { aquí considerados, describir de manera muy precisa lo realizado } \\
\text { en el taller, pero especificando participantes, materiales, lugar en } \\
\text { el que se lleva a cabo, técnica de recopilación de la información y } \\
\text { categorías de análisis; todos estos elementos, necesarios para dar } \\
\text { cuenta de una investigación de corte cualitativo. Adicional a esto, } \\
\text { como se suele hacer en investigación de corte cualitativo y sobre } \\
\text { todo cuando se trata de investigación-implicación, es importante } \\
\text { aclarar sobre la confidencialidad de lo trabajado con el grupo, as } \\
\text { como aquello que se le devuelve al terminar el taller. }\end{array}$ \\
\hline \multicolumn{2}{|c|}{ Resultados } \\
\hline $\begin{array}{l}\text { Como se comentaba anteriormente, la relación entre lo de- } \\
\text { sarrollado en el parco teórico y los resultados (de los que } \\
\text { derivarán las conclusiones) es pobre, por lo que debe traba- } \\
\text { jarse esta parte. }\end{array}$ & $\begin{array}{l}\text { Es importante mencionar que muchos de los elementos que se } \\
\text { evelúan en esta sección de resultados no aplican para una in- } \\
\text { vestigación de corte cualitativo, adicional a esto, la problemática } \\
\text { descrita anteriormente en cuanto a los múltiples objetivos que } \\
\text { aparecen en el artículo, hace que la evaluación sea menor en esta } \\
\text { sección tomando en cuenta la cuestión de los resultados. Hacien- } \\
\text { do las adecuaciones respecto a los objetivos, esto se soluciona- } \\
\text { ría de inmediato. Por último, la descripción de los resultados se } \\
\text { muestra muy somera. Aun cuando se describen dos experiencias } \\
\text { de violencia representadas por los estudiantes dentro del taller } \\
\text { pareciera que pueden aprovecharse muchos más elementos de } \\
\text { las mismas; sobre todo pensando que el marco teórico de este } \\
\text { artículo es el psicoanálisis, el uso y análisis de fragmentos de lo } \\
\text { dicho y expresado (además de las risas) podrían posibilitar un } \\
\text { análisis mucho más rico para efectos del objetivo. }\end{array}$ \\
\hline \multicolumn{2}{|c|}{ Discusión } \\
\hline $\begin{array}{l}\text { Ésta es quizá la sección más débil del estudio, ya que la pro- } \\
\text { yección de lo tratado en el marco teórico no se despliega } \\
\text { correctamente aquí, por lo que la lógica del estudio parece } \\
\text { endeble. }\end{array}$ & $\begin{array}{l}\text { Se agrupan en el artículo, tanto Discusión como Conclusio- } \\
\text { nes, y si bien esto no es un error, sí se presentan demasiado } \\
\text { someras. Al igual que se comentó anteriormente, el análisis } \\
\text { de los dichos, chistes, palabras, risas, en fin, fragmentos de } \\
\text { lo ocurrido (dicho) en las representaciones descritas, puede } \\
\text { aportar muchos más elementos de análisis que los que aqui } \\
\text { se incluyen. }\end{array}$ \\
\hline
\end{tabular}




\begin{tabular}{|l|l|}
\hline \multicolumn{2}{|c|}{ Revisor 1 Conclusiones } \\
\hline \multicolumn{2}{|c|}{ Revisor 2 } \\
\hline $\begin{array}{l}\text { Los comentarios de esta sección van dirigidos a las mismas } \\
\text { adolescencias ya versadas anteriormente. }\end{array}$ & $\begin{array}{l}\text { Para este apartado, repito mi comentario anterior: Se agrupan } \\
\text { en el artículo, tanto Discusión como Conclusiones, y si bien } \\
\text { esto no es un error, sí se presentan demasiado someras. Al igual } \\
\text { que se comentó anteriormente, el análisis de los dichos, chistes, } \\
\text { palabras, risas, en fin, fragmentos de lo ocurrido (dicho) en las } \\
\text { representaciones descritas, puede aportar muchos más elemen- } \\
\text { tos de análisis que los que aquí se incluyen. }\end{array}$ \\
\hline \multicolumn{1}{|c|}{ Referencias } \\
\hline $\begin{array}{l}\text { Deberían acompañarse las referencias clásicas con otras más } \\
\text { actuales (lo cual ya se había acotado). También debe respe- } \\
\text { tarse el formato APA, lo cual no se hace a lo largo dela artí- } \\
\text { culo, y la lista de referencias no es la excepción. }\end{array}$ & $\begin{array}{l}\text { Los autores clásicos como Freud, Massota y Bourdieu incluso, } \\
\text { por supuesto no necesitan estar "actualizados", el resto de las } \\
\text { referencias bibliográficas son adecuadas al tema y varias de ellas } \\
\text { de autores contemporáneos. Sin embargo, podría ser un muy } \\
\text { buen aporte revisar algunas otras contribuciones psicoanalíti- } \\
\text { cas al tema del humor y la violencia. }\end{array}$ \\
\hline
\end{tabular}




\section{Historia del Proceso}

\section{EDITORIAL}

